\title{
Long-term prevalence of post-traumatic stress disorder symptoms in patients after secondary peritonitis
}

\author{
Kimberly R Boer ${ }^{1}$, Cecilia W Mahler ${ }^{2}$, Cagdas Unlu², Bas Lamme ${ }^{2}$, Margreeth B Vroom³, \\ Mirjam A Sprangers ${ }^{4}$, Dirk J Gouma ${ }^{2}$, Johannes B Reitsma ${ }^{1}$, Corianne A De Borgie ${ }^{1}$ and \\ Marja A Boermeester ${ }^{2}$
}

\author{
1Department of Clinical Epidemiology \& Biostatistics, Academic Medical Center, Amsterdam, The Netherlands \\ 2Department of Surgery, Academic Medical Center, Amsterdam, The Netherlands \\ ${ }^{3}$ Department of Intensive Care Medicine, Academic Medical Center, Amsterdam, The Netherlands \\ ${ }^{4}$ Department of Medical Psychology, Academic Medical Center, Amsterdam, The Netherlands \\ Corresponding author: Marja A Boermeester, m.a.boermeester@amc.uva.nl
}

Received: 19 Sep 2006 Revisions requested: 7 Nov 2006 Revisions received: 10 Jan 2007 Accepted: 23 Feb 2007 Published: 23 Feb 2007

Critical Care 2007, 11:R30 (doi:10.1186/cc5710)

This article is online at: http://ccforum.com/content/11/1/R30

(c) 2007 Boer et al.; licensee BioMed Central Ltd.

This is an open access article distributed under the terms of the Creative Commons Attribution License (http://creativecommons.org/licenses/by/2.0), which permits unrestricted use, distribution, and reproduction in any medium, provided the original work is properly cited.

See related commentary by Weinert and Meller, http://ccforum.com/content/11/1/118

related research by Jackson et al., http://ccforum.com/content/11/1/R27

and related research by Girard et al., http://ccforum.com/content/11/1/R28

\begin{abstract}
Introduction The aim of this study was to determine the longterm prevalence of post-traumatic stress disorder (PTSD) symptomology in patients following secondary peritonitis and to determine whether the prevalence of PTSD-related symptoms differed between patients admitted to the intensive care unit (ICU) and patients admitted only to the surgical ward.
\end{abstract}

Method A retrospective cohort of consecutive patients treated for secondary peritonitis was sent a postal survey containing a self-report questionnaire, namely the Post-traumatic Stress Syndrome 10-question inventory (PTSS-10). From a database of 278 patients undergoing surgery for secondary peritonitis between 1994 and 2000, 131 patients were long-term survivors (follow-up period at least four years) and were eligible for inclusion in our study, conducted at a tertiary referral hospital in Amsterdam, The Netherlands.

Results The response rate was $86 \%$, yielding a cohort of 100 patients; $61 \%$ of these patients had been admitted to the ICU. PTSD-related symptoms were found in 24\% (95\% confidence interval $17 \%$ to $33 \%$ ) of patients when a PTSS-10 score of 35 was chosen as the cutoff, whereas the prevalence of PTSD symptomology when borderline patients scoring 27 points or more were included was 38\% (95\% confidence interval $29 \%$ to $48 \%$ ). In a multivariate analyses controlling for age, sex, Acute Physiology and Chronic Health Evaluation II (APACHE II) score, number of relaparotomies and length of hospital stay, the likelihood of ICU-admitted patients having PTSD symptomology was 4.3 times higher (95\% confidence interval 1.11 to 16.5 ) than patients not admitted to the ICU, using a PTSS-10 score cutoff of 35 or greater. Older patients and males were less likely to report PTSD symptoms.

Conclusion Nearly a quarter of patients receiving surgical treatment for secondary peritonitis developed PTSD symptoms. Patients admitted to the ICU were at significantly greater risk for having PTSD symptoms after adjusting for baseline differences, in particular age.

APACHE = Acute Physiology and Chronic Health Evaluation; ARDS = acute respiratory distress syndrome; $\mathrm{Cl}=$ confidence interval; $\mathrm{DSM}=$ Diagnostic and Statistical Manual of Mental Disorders; ICU = intensive care unit; MPI = Mannheim Peritonitis Scale; OR = odds ratio; PTSD = post-traumatic stress disorder; PTSS-10 = Post-traumatic Stress Syndrome 10-question inventory; SCID = Structured Clinical Interview for DSM-IV Axis II Personality Disorders. 


\section{Introduction}

Peritonitis or abdominal sepsis is a severe disease with high mortality (approximately 30\%) [1,2]. Intensive care unit (ICU) and hospital admission may be lengthy and morbidity extensive. Hence, experiencing peritonitis is a major life event. Patients who survive critical illness often report poor quality of life and exhibit post-traumatic stress disorder (PTSD) symptomology during the post-clinical period [3-8]. PTSD symptoms include intrusive recollections, avoidant/numbing symptoms and hyperarousal symptoms resulting from exposure to one or more traumatic events [9]. Patients with PTSD (symptoms) have reduced quality of life $[6,8,10-12]$ and frequently suffer from depression $[8,13]$. Therefore, monitoring PTSD symptomology in ICU patients could complement hospital and longterm survival outcomes, guide early sociopsychological interventions and improve long-term patient care. Hence, it is worth evaluating PTSD in order to elucidate the complex nature of long-term outcomes in this setting [14].

Many survivors of critical illness and its treatment suffer from continuous traumatic memories and re-live adverse experiences from their illness, such as respiratory distress, anxiety, pain and loss of control, which are all associated with an increased risk for development of PTSD $[3,6]$. Studies have reported prevalence rates of $15 \%$ to $38 \%$ for PTSD-related symptoms in patients who had been admitted to the ICU $[4,8]$. Some authors have argued that specific circumstances and memories during the ICU stay can serve as a trigger for developing PTSD symptoms rather than having a severe underlying illness itself. However, the majority of studies examining the relation between ICU stay and PTSD symptoms were conducted in cohorts in which all patients had been admitted to the ICU, rendering these studies unable to differentiate between ICU and non-ICU patient experiences.

In addition, data on the prevalence of PTSD-related symptoms following secondary peritonitis are lacking. It is unknown whether the prevalence of symptoms related to PTSD or memories of traumatic experiences differ between peritonitis patients after ICU admission (who have undergone surgery, ICU stay and hospital ward stay) and patients without ICU admission (who have undergone surgery and hospital ward stay only).

The aim of the present study was first to determine the longterm prevalence of PTSD symptomology in patients 4 to 10 years after secondary peritonitis based on a self-report questionnaire. We also aimed to compare the prevalence of PTSDrelated symptoms between patients admitted to the ICU and patients admitted only to the surgical ward. Finally, we examined whether the prevalence of PTSD symptomology in these patients was increased because of the traumatic memories that patients had during their ICU and/or hospital stay [1].

\section{Materials and methods Study population}

A retrospective cohort of 278 consecutive patients, who were treated surgically for secondary peritonitis between January 1994 and January 2000, was the starting cohort in the study [1]. All patients were treated at the Department of Surgery in the Academic Medical Center at the University of Amsterdam, The Netherlands. All patients who were still alive at follow up were eligible for inclusion. These patients were informed about the study by telephone in order to improve the response rate. Because of the noninterventional nature of the study, the institutional review board waived the need for informed consent.

\section{Data collection}

All patients still alive at follow up were eligible for the study ( $n$ $=118$ ) and received a standardized instrument for assessing symptoms related to PTSD, namely the Posttraumatic Stress Scale 10-question inventory (PTSS-10). In addition, they received a four-question Adverse Experiences Questionnaire. Each questionnaire addressed the patient's feelings over the preceding 14 days. Patients who had been admitted to the ICU during their hospital stay for peritonitis were sent a questionnaire that specifically asked the patient to consider their feelings during the preceding 14 days while keeping their past ICU stay in mind. Patients not admitted to the ICU were asked to complete the questionnaire for the preceding 14 days keeping in mind their past stay in the general ward following their episode of peritonitis.

A separate questionnaire was included to collect relevant clinical data following discharge from the hospital for peritonitis (including readmissions since discharge after surgical treatment for secondary peritonitis and use of medication during the preceding few years, and newly developed diseases and their treatment).

Patients who returned incomplete questionnaires were contacted by phone within two weeks in an attempt to complete the questionnaire by phone. Patients who did not return the questionnaires were sent the questionnaires two more times within a six week period. After these attempts had been made, patients who had given initial telephone consent were contacted again to obtain information regarding their motivations for not responding.

Demographic and clinical data at the time of the index surgical procedure (the emergency laparotomy performed at initial presentation of peritonitis) were collected from hospital charts and computerized registration system. The following information was recorded: age, sex, comorbidity, use of medication, Acute Physiology and Chronic Health Evaluation [APACHE] II score before surgery and Mannheim Peritonitis Index (MPI). Disease and surgical characteristics recorded contained aetiology of peritonitis, origin of peritonitis, surgical treatment strategy and number of relaparotomies. Postoperative charac- 
teristics recorded included the number of days spent in hospital, the number of days spent in the ICU, days of mechanical ventilation, 'open abdomen' (laparostomy) during admission, number and type of complications, number of readmissions and the mean follow-up time. Patient recall was checked using the hospital information and medication system to check readmission and use of medication. Details regarding out-ofhospital medications, such as those prescribed by the family physician, were obtained only by questionnaire.

\section{Instruments}

Post-traumatic Stress Syndrome 10-question inventory The PTSS-10 was originally designed to diagnose PTSD, according to Diagnosis and Statistical Manual of Mental Disorders (DSM)-II criteria, in victims of natural disasters [15], and it was subsequently validated in Norwegian seaman after they had undergone torture in Libya [16]. The PTSS-10 has since been validated in patients with acute respiratory distress disorder (ARDS) after ICU treatment using the Structured Clinical Interview for DSM-IV (SCID) Axis II Personality Disorders [9]. The PTSS-10 is now a widely used and validated selfreport questionnaire; it has been reported to achieve a sensitivity of $77 \%$ and a specificity of $97.5 \%$ for the diagnosis of PTSD [17].

The questionnaire consists of 10 items, each with a Likert scale ranging from 1 ('never') to 7 ('always'). A summated score with a range between 10 and 70 is calculated, with higher scores indicating more PTSD-related symptoms. A score of 35 or greater is considered an adequate cutoff for PTSD-related symptomology [11,17-19], whereas patients with scores between 27 and 35 on PTSS-10 were considered to have borderline PTSD symptomology. The validated English version was translated into Dutch according to a forwardbackward translation procedure.

\section{Adverse events/traumatic experiences questionnaire}

The four-item Adverse Experiences Questionnaire assesses the presence of four types of traumatic memories during a stay in the ICU or hospital ward [17]: anxiety, respiratory distress, pain, and/or nightmares. Patients scored the frequency with which they experienced these traumatic events (or their recollection of them) during their stay in the ICU or hospital ward using a 4-point response scale: $1=$ none, 2 = sometimes, $3=$ regularly and $4=$ often.

\section{Analysis}

Ninety-five per cent confidence intervals around estimates of prevalence were calculated using the method of Wilson [20]. Clinical characteristics and the prevalence of PTSD symptoms between patients who were admitted to ICU during their initial stay and those who were treated solely on the surgical ward were compared. Depending on the nature of the clinical variables, we used Pearson $\chi^{2}$, Student's $t$, or Mann-Whitney $U$ tests.
We built multivariate logistic regression models to assess the association between ICU stay and the presence of PTSD symptomology (PTSS-10 score $>35$ ) after adjusting for other factors. We adjusted for factors related to patient characteristics (age [continuous] and sex), disease characteristics (APACHE-II score at baseline [continuous] and whether patients had undergone one or more relaparotomies [yes/no]) and postoperative characteristics (days spent in hospital [transformed to base 10 in order to improve the linear relationship with outcome]) [21]. These factors were chosen either because they were identified in earlier PTSD studies and literature [21] (for instance, age, sex and comorbidity) or because they exhibited univariate significance $(P<0.1)$ with the dependent factor (PTSD symptomology) in our study (APACHE II score, patients undergoing more than one relaparotomy and days in hospital). If factors were highly correlated, we selected only one of the correlated factors in the multivariate model to avoid the problem of co-linearity. Odds ratios with $95 \%$ confidence intervals (Cls) were used to quantify the strength of the association. To determine the fit of the final multivariate logistic model, we calculated the area under the receiver operating characteristic curve, also known as the concordance statistic, and performed the Hosmer-Lemeshow goodness-of-fit test.

To determine whether traumatic memories acquired during the stay in hospital or the ICU played a role in the development of PTSD symptomology, we examined the percentage of patients with PTSD symptomology within each level of response on the traumatic memories questions. Because of the ordered response on the traumatic memories questions, we used the $\chi^{2}$ test for trend to examine this relation.

$P<0.05$ were considered statistically significant.

\section{Results}

From the initial cohort of 278 patients with secondary peritonitis [1], 118 patients were long-term survivors. These patients received the set of questionnaires, and 104 patients (88\%) responded (Figure 1). Of the 14 patients who did not respond to the questionnaire, five patients were not willing to complete the questionnaire and nine patients, who were initially informed about the study by phone before the mailing, could not be contacted again to find out the reason for not responding to the questionnaire. Four patients were excluded because too many data were missing (Figure 1). No significant differences in operative, hospital-related, or postoperative characteristics were found between patients suitable for analysis $(n=100)$ and eligible patients still alive who did not respond $(n=32)$. However, comparison of patient characteristics between the two groups revealed that patients in the nonresponding group were younger (mean 51 years versus 40 years; $P<0.001$ ), presented with fewer comorbidities (comorbidity present in $65 \%$ versus $30 \% ; P<0.001)$ at initial surgery, and had lower APACHE II scores ( 9.5 versus $7.5 ; P=0.049$ ) and MPI scores 
Figure 1

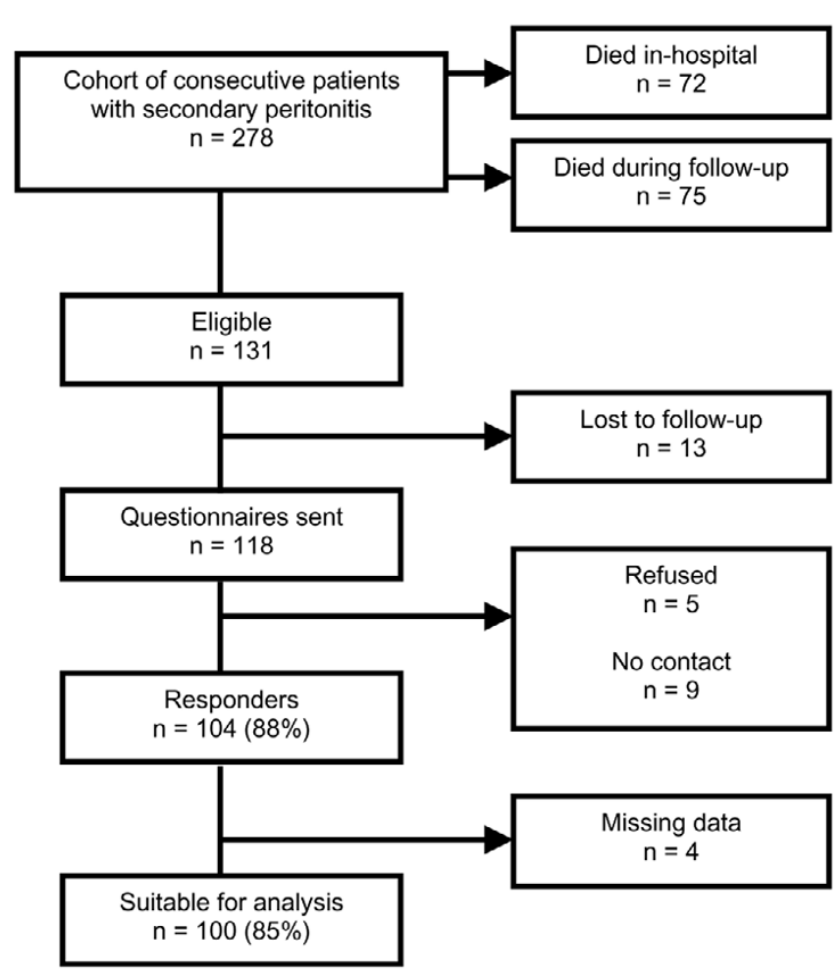

Flowchart of study inclusion.

(22 versus $18.6 ; P=0.024$ ) than did patients in the responder group. There was no difference between responding patients and nonresponders in ICU admittance.

In responding patients the average interval between index operation and follow up was 5.3 years for ICU and non-ICU patients. Comorbidity was present in $65 \%$ of patients, and nearly $80 \%$ of patients were on some type of medication (Table 1). The APACHE II score (mean \pm standard deviation) at the time of the index operation was $9.5 \pm 5$ and the MPI score was $21.9 \pm 7$. Seventy-six per cent of patients were treated using an on-demand relaparotomy strategy and $24 \%$ were managed according to a planned relaparotomy strategy; overall, $59 \%$ of patients underwent one or more re-laparotomies.

\section{Post-traumatic stress disorder symptomology}

The median PTSS-10 score among all patients was 22 , with $25 \%$ of the patients having a score below 13 and $25 \%$ of patients with a score above 33 . Using the recommended cutoff value for PTSD symptomology of 35 points on the PTSS10 questionnaire $[17,19,22,23]$, the overall prevalence of PTSD-related symptoms was $24 \%$ (95\% Cl $17 \%$ to $33 \%)$. The overall prevalence of PTSD symptomology including borderline patients who scored 27 points or more was $38 \%$ (95\% Cl $29 \%$ to $48 \%$ ).

\section{Comparison between ICU and non-ICU patients}

Patient, disease and operative characteristics for ICU patients (61\%) and non-ICU patients (39\%) are presented in Table 1. Patients who had had an ICU stay were on average 7.5 years older than patients who were not admitted to the ICU $(P=$ 0.011). ICU patients also had higher APACHE II score (mean difference 2.2 points; $P=0.037$ ) and MPI score (mean difference 3.2 points; $P=0.036$ ). Of patients who had had an ICU stay $36 \%$ underwent laparostomy (open abdomen), whereas only $8 \%$ of the ward patients underwent laparostomy (in $92 \%$ of patients admitted to the surgical ward primary abdominal closure was done; $P=0.001$ ). A relaparotomy was significantly more common in the ICU group than in the non-ICU group ( $72 \%$ versus $40 \%$; $P<0.001$ ).

With respect to postoperative characteristics, patients had a median stay in hospital of 37 days. ICU survivors had a longer hospital stay than did non-ICU survivors (median days: 49 versus $27 ; P=0.001$ ) and suffered more nonsurgical complications $(57 \%$ versus $8 \% ; P<0.001)$. Fifty-four $(89 \%)$ patients required mechanical ventilation during their ICU stay. These patients were ventilated for a median of 11 days. Four of the ICU-admitted patients suffered early ARDS (within 96 hours) following peritonitis.

\section{Post-traumatic stress disorder symptoms}

In an univariate analysis, using a PTSS-10 score above 35 as the cutoff, we found a prevalence of PTSD symptomology of $18 \%(7 / 39)$ in the non-ICU group and 28\% (17/61) in the ICU group $(P=0.21)$. We examined several factors to determine whether they confounded the strength of the relationship between ICU stay and the probability of having relevant PTSD symptomology (Table 2). After controlling for age, sex, APACHE II score, relaparotomy and length of hospital stay in a multivariate analysis, patients admitted to the ICU were more likely to report PTSD symptomology on the PTSS-10 questionnaire than patients admitted to the surgery ward only (

Other factors that were significantly associated with more PTSD symptoms in the multivariate model included gender, age, and severity of disease at initial surgery. Females were more likely to develop PTSD symptoms than were males (OR $3.5,95 \% \mathrm{Cl} 1.2$ to 10.6$)$. With every one-year decrease in age, the likelihood of developing PTSD symptoms decreased (OR $0.93,95 \% \mathrm{Cl} 0.89$ to 0.98 ). Finally, with every point increase in APACHE-II score, the chances of developing PTSD symptoms increased (OR 1.1, 95\% Cl 1.002 to 1.25). Therefore, the main reason for finding a stronger relation between ICU stay and PTSD symptomology in the multivariate model is that older patients are less likely to develop PTSD symptoms. Because ICU patients on average were older than non-ICU patents, the unadjusted relationship underestimated the effect of ICU on PTSD symptoms. Males were also less likely to report PTSD symptomology (OR 0.95, 95\% Cl 0.91 to 0.98 ), but because of the comparable sex distribution in 
Table 1

\section{Characteristics of study population}

\begin{tabular}{|c|c|c|c|c|}
\hline \multirow[t]{2}{*}{ Type of characteristics } & \multicolumn{3}{|c|}{ Patients } & \multirow[t]{2}{*}{$\begin{array}{c}P \text { value } \\
\text { (non-ICU versus ICU) }\end{array}$} \\
\hline & $\begin{array}{c}\text { Overall } \\
(n=100)\end{array}$ & $\begin{array}{l}\text { Non-ICU } \\
(n=39)\end{array}$ & $\underset{(n=61)}{\text { ICU }}$ & \\
\hline \multicolumn{5}{|c|}{ Patient characteristics at index operation } \\
\hline Age (years; mean $\pm \mathrm{SD}$ ) & $51.1 \pm 14$ & $46.7 \pm 15$ & $54.2 \pm 13$ & $0.011^{a}$ \\
\hline Male sex (\% $[n])$ & $59 \%(60)$ & $51 \%(20)$ & $64 \%(39)$ & $0.21^{b}$ \\
\hline Comorbidity $(\%[n])$ & $65 \%(66)$ & $67 \%(26)$ & $65 \%(40)$ & $0.91^{b}$ \\
\hline Use of any medication $(\%[n])$ & $77 \%(78)$ & $82 \%(32)$ & $78 \%(46)$ & $0.62^{b}$ \\
\hline APACHE II score (mean \pm SD) & $9.5 \pm 5.2$ & $8.2 \pm 5$ & $10.4 \pm 5$ & 0.037 \\
\hline MPI score (mean \pm SD) & $21.9 \pm 7.4$ & $20.0 \pm 8$ & $23.2 \pm 7$ & $0.036^{a}$ \\
\hline
\end{tabular}

Disease and operative characteristics

Aetiology of peritonitis (\% [n])

Perforation

Anastomotic leakage

Ischaemia

Pancreatitis

Bile leakage

Abcess

Other

Origin of peritonitis $(\%[n])$

Colon

Small intestine
$0.29 \mathrm{~b}$

$\begin{array}{lcc}39 \%(39) & 42 \%(17) & 36 \%(22) \\ 26 \%(26) & 25 \%(10) & 26 \%(16) \\ 5 \%(5) & 8 \%(5) \\ 7 \%(7) & 2 \%(1) & 9 \%(6) \\ 7 \%(7) & 10 \%(4) & 4 \%(3) \\ 9 \%(9) & & 9 \%(6) \\ 7 \%(7) & 12 \%(4) & 4 \%(3)\end{array}$

$25 \%(25) \quad 25 \%(10) \quad 25 \%(15)$ 
Critical Care Vol 11 No 1 Boer et al.

Table 1 (Continued)

\section{Characteristics of study population}

$\begin{array}{lccr}\text { Pancreas } & 13 \%(13) & 3 \%(1) & 20 \%(12) \\ \text { Appendix } & 4 \%(4) & 5 \%(2) & 3 \%(2) \\ \text { Gall bladder } & 4 \%(4) & 5 \%(2) & 3 \%(2) \\ \text { Stomach/duodenum } & 6 \%(6) & 5 \%(2) & 8 \%(5)\end{array}$

Treatment strategy $(\%[n])$

$0.11^{b}$

On demand

Planned relaparotomy

Laparostomy (open abdomen) during admission (\% [ $n]$ )

Patients with $=1$ relaparotomy $(\%[n])$
$76 \%(77)$

$85 \%(33)$

$15 \%(6)$

$8 \%(3)$

$25 \%(25)$

$59 \%(60)$

$40 \%(16)$

$0.001^{b}$

$36 \%(22)$

$0.002^{b}$

Postoperative characteristics

Days in hospital (median [25th to 75th percentile])

Days in ICU (median [25th to 75th percentile])c

Patients mechanically ventilated $(\%[n])^{c}$

Days of mechanical ventilation (median [25th to 75th percentile]) ${ }^{c}$

Complications $(\%[n])$

\section{Surgery related}

Sepsis related

Readmission to hospital (\% $[n])$

Time since index operation
$37.0(21$

27.0 (17 to 41$)$

$49.0(27$ to 73$)$

$<0.001^{\mathrm{a}}$

$16.0(5$ to 30$)$

NA

$89 \%(54)$

n.a.
$11.0(4$ to 25$) \quad$ n.a.

Time of questionnaire receipt since index operation (months; median [min-max])

88.6 (49 to 127$)$

$88.4(50$ to 122$)$

88.5 (49 to 127$)$

$0.99^{a}$

aT-test or Mann-Whitney U-test. bPearson's or Fischer's exact $\chi^{2}$. conly patients who were admitted to the ICU $(n=61)$. APACHE, Acute Physiology and Chronic Health Evaluation; ICU, intensive care unit; MPI, Mannheim Peritonitis Scale; NA, not applicable; SD, standard deviation. 
Multivariable logistic regression analysis for factors associated with the presence of PTSD symptomology

\begin{tabular}{|c|c|c|c|}
\hline & \multicolumn{2}{|c|}{ PTSS-10 sum score } & \multirow[t]{2}{*}{ Adjusted ORa $(95 \% \mathrm{Cl})$} \\
\hline & Patients with scores $>35(n=24)$ & Patients with scores $<35(n=76)$ & \\
\hline Patients admitted to the ICU (\%) & $71 \%$ & $57 \%$ & $4.3(1.11$ to 16.5$)$ \\
\hline Females $(\%)$ & $54 \%$ & $37 \%$ & $3.5(1.2$ to 10.6$)$ \\
\hline Age (years; mean $\pm \mathrm{SD}$ ) & $52.9 \pm 14.9$ & $59.8 \pm 14.1$ & $0.93^{b}(0.89$ to 0.98$)$ \\
\hline APACHE II score (mean \pm SD) & $10.7 \pm 5.8$ & $9.1 \pm 5.0$ & $1.1^{\mathrm{c}}(1.002$ to 1.25$)$ \\
\hline$\geq 1$ Relaparotomy $(\%)$ & $63 \%$ & $59 \%$ & $3.8(0.86$ to 16.8$)$ \\
\hline Hospital stay (days; median [25th to 75 th percentile]) & $46(28$ to 54$)$ & 33 (21 to 59$)$ & $2.2^{\mathrm{e}}(0.8$ to 5.8$)$ \\
\hline
\end{tabular}

aThe odds ratio (OR) has been adjusted for sex, age, Acute Physiology and Chronic Health Evaluation (APACHE) II score, $\geq 1$ relaparotomy and length of hospital stay. ${ }^{b}$ Per one-year increase in age, the odds ratio (OR) for having post-traumatic stress disorder (PTSD) symptoms decreased by 0.93 . cPer one-point increase in APACHE II score, the OR for having PTSD symptoms increased by 1.1. dIn the logistical model hospital stay is $\log$ to the base 10 transformed. eFor one patient hospital discharge dates were missing, and therefore information regarding length of hospital stay was missing; imputation was done using the mean duration of stay for the non-ICU stay group; one patient was missing APACHE II score data. PTSS-10, Post-traumatic Stress Syndrome 10-question inventory; SD, standard deviation.

ICU and non-ICU patients it did not confound the relation between ICU stay and PTSD symptomology (Table 2). Length of hospital stay was associated with more PTSD symptomology, and it was therefore also a confounder for the relation between ICU stay and PTSD symptomology because hospital stay was markedly longer in ICU patients than in non-ICU patients. The area under the receiver operating characteristic curve for the final multivariate model was 0.77 (95\% Cl 0.66 to 0.88$)$. This indicates that if we were to randomly choose one patient above the PTSS-10 cutoff value and one patient below, the probability that the patient above the cutoff would have a higher predicted risk for PTSD symptomology based on the model is $79 \%$. Differences in observed versus predicted probabilities were small, with the Hosmer-Lemeshow test yielding a $P$ value of 0.41 .

\section{Traumatic memories and symptoms of post-traumatic stress disorder}

In the total study population, traumatic memories were associated with more PTSD symptomology (Table 3). Patients reporting more traumatic memories during their ICU or hospital stay reported significantly more PTSD symptoms on the PTSS-10. Patients with nightmares, panic attacks, intense pain and difficulty breathing during their ICU or hospital ward stay had higher median scores than did patients reporting no traumatic memories from the ICU or hospital ward (Table 3). There were, however, no statistically significant differences between the ICU group and the non-ICU group of patients with respect to reporting of traumatic memories (nightmares: $\chi^{2}=5.84, P=0.12$; fear or panic attacks: $\chi^{2}$ odds ratio [OR] 4.3, 95\% Cl 1.11 to 16.5$)=6.9, P=0.075$; pain: $\chi^{2}=1.01$, $P=0.80$; and difficulty breathing: $\left.\chi^{2}=5.3, P=0.15\right)$.

\section{Discussion}

Our cohort of patients experiencing the same acute disease includes both patients who have been admitted to the ICU and those who were treated on the surgical ward only. This ena- bled us to conduct a detailed analysis of the impact of ICU stay on long-term PTSD symptomology. We found a high overall prevalence of long-term PTSD symptomology, as indicated by the PTSS-10 questionnaire, many years after surgical treatment for secondary peritonitis. The proportion of patients scoring above the 35 -point threshold on PTSS-10 was $24 \%$.

The PTSS-10 is an instrument specifically designed to identify PTSD symptoms in ICU patients. The prevalence of PTSD symptoms in our patients was similar to that in a retrospective study conducted in ARDS patients in 1998 using the PTSS10 [6], and it was similar to that in ARDS patients studied in 2004 (median follow up eight years) in which 24\% of patients suffered full-blown PTSD (as diagnosed using SCID) [11]. Past studies found a lifetime prevalence of $7.8 \%$ to $8.3 \%$ in the US general population in the 1990s [24], but more recently a study conducted in six European countries (the European Study Of The Epidemiology Of Mental Disorders [ESEMeD] study) $[25,26]$ estimated a considerably lower prevalence of PTSD, varying between $0.9 \%$ and $2.9 \%$. Compared with these general populations, the proportions of patients from an ICU population with PTSD symptomology, a considerable time after discharge, are high [13,25-28].

We found that patients who responded to the PTSS-10 questionnaire exhibited higher APACHE II scores and MPI scores, and increased comorbidity than did patients who did not respond to the questionnaire. These differences might have led to a small overestimation of the prevalence of PTSD symptoms ( $n=100$ ). However, our patient group had an overall lower mean APACHE II score than that reported in other ICU populations with similar prevalence of PTSD symptoms. Although the APACHE II scores of patients admitted to the ICU in our study are lower than those in other studies on PTSD symptoms using the PTSS-10 questionnaire [3,4], the APACHE II scores are not particularly low for a population of patients with peritonitis [1]. 
Table 3

Traumatic memories during ICU/hospital stay in relation to PTSS-10 score

\begin{tabular}{|c|c|c|}
\hline $\begin{array}{l}\text { Traumatic memories or adverse } \\
\text { experiences during ICU/hospital stay }\end{array}$ & $\begin{array}{l}\text { Percentage of patients with PTSS-10 } \\
\text { sum score above } 35(n=24)\end{array}$ & $P$ value (for trend) \\
\hline \multicolumn{3}{|l|}{ Nightmares } \\
\hline Never $(n=42)$ & 9.5 & \\
\hline Sometimes $(n=29)$ & 24.1 & 0.001 \\
\hline Regularly $(n=20)$ & 45.0 & \\
\hline Often $(n=9)$ & 44.4 & \\
\hline \multicolumn{3}{|l|}{ Fear or panic attacks } \\
\hline Never $(n=53)$ & 9.4 & \\
\hline Sometimes $(n=23)$ & 26.1 & $<0.001$ \\
\hline Regularly $(n=16)$ & 50.0 & \\
\hline Often $(n=8)$ & 62.5 & \\
\hline \multicolumn{3}{|l|}{ Intense pain } \\
\hline Never $(n=27)$ & 7.4 & \\
\hline Sometimes $(n=35)$ & 17.1 & 0.007 \\
\hline Regularly $(n=15)$ & 60.0 & \\
\hline Often $(n=23)$ & 30.4 & \\
\hline \multicolumn{3}{|l|}{ Difficulty breathing } \\
\hline Never $(n=50)$ & 12.0 & \\
\hline Sometimes $(n=30)$ & 33.3 & 0.014 \\
\hline Regularly $(n=9)$ & 44.4 & \\
\hline Often $(n=11)$ & 36.4 & \\
\hline
\end{tabular}

a $\chi^{2}$ test for linear trend. ICU, intensive care unit; PTSS-10, Post-traumatic Stress Syndrome 10-question inventory.

In a univariate analysis we found no significant differences in the prevalence of PTSD symptoms between ICU (28\%) and non-ICU patients (18\%) on the PTSS-10. However, ICU stay was independently associated with PTSD symptomology after adjusting for other factors related to PTSD, in particular age. As expected, when comparing ICU patients with non-ICU patients, differences were found in patient, disease, operative and postoperative characteristics. ICU patients were older and had more severe disease (based on the recorded APACHE II score), more surgical interventions and longer hospital stay, all of which could have affected their eventual PTSD symptomology. To control for these differences and to determine whether ICU was an independent factor for PTSD, we created a multivariate model. When controlling for age, sex, APACHE II score, having undergone one or more relaparotomy, and length of hospital stay in the postoperative period, we found a significant difference in the prevalence of PTSD symptomology (based on PTSS-10 score) between patients with and without an ICU stay. Older age and being male had a protective role, whereas higher APACHE II scores led to more PTSD symptoms. These findings are in contrast to earlier data, in which no associations between higher APACHE II score and greater probability of developing of PTSD symptoms were identified $[4,5]$. It is important to note that even the non-ICU group exhibited a relatively high prevalence of PTSD-related symptoms. This suggests not only the ICU environment but also secondary peritonitis per se may be a sufficiently traumatic event for a patient to develop PTSD.

Because mechanical ventilation has previously been associated with development of more PTSD-like symptoms after ICU treatment [29], this might be the reason why our ICU patients also exhibited more PTSD symptomology than did the surgery ward only patients. Because nearly all of our ICU patients were mechanically ventilated, we could not determine the independent impact of these two factors.

Because of the retrospective nature of the study, details concerning the severity of sepsis (such as septic shock status on admission and hydrocortisone use during the ICU stay) could not be ascertained as risk factors in all patients [12,23]. These factors could be important in the development of PTSD symptoms in ICU patients. The importance of hydrocortisone use in the ICU and the development of PTSD symptoms has previ- 
ously been highlighted [12,23]. A randomized study [23] showed that introduction of hydrocortisone treatment into the regimen during an ICU stay reduces subsequent development of PTSD symptoms. In past studies ARDS has been demonstrated to be an independent predictor of developing PTSD symptoms; patients suffering from ARDS were found to exhibit more PTSD symptoms $[6,10,11]$, but in the present study we only had data on development of ARDS within the first four days after peritonitis. Risk factors in the ICU environment such as ARDS, septic shock and mechanical ventilation (the vast majority of the study patients admitted to the ICU were ventilated) could, at least in part, account for the differences in PTSD symptoms between patients in the ICU those those managed on surgical wards only.

There were no differences in the number of traumatic memories reported between ICU patients and the patients managed on the surgical ward only, although we found a clear positive linear association between more traumatic memories and higher scores on the PTSS-10. This relation between traumatic memories and the PTSS-10 score was also found in two earlier studies conducted in ICU patients $[6,30]$. We anticipated that the ICU environment would create more traumatic memories, which would in turn lead to more PTSD-related symptoms. However, the proportion of patients with traumatic memories was comparable between ICU and non-ICU patients.

\section{Limitations}

Ideally, PTSD is diagnosed using a SCID [23], in accordance with the DSM-IV [9]. SCID is a semi-structured diagnostic interview designed to allow clinicians and researchers to make reliable DSM-IV psychiatric diagnoses. In recent studies it has been established that a self-report PTSS-10 questionnaire can be as useful a tool in determining which patients are suffering from PTSD symptomology $[5,17]$. These studies found significantly higher PTSS-10 scores in patients with a SCID-II PTSD diagnosis than in patients without. The sensitivity in these studies varied from $77 \%$ to $100 \%$, and specificity from $92 \%$ to $98 \%$ when using a cutoff score of $35[5,17]$. However, these estimates were imprecise because of the small sample sizes in these studies. It is unclear to what extent sensitivity and specificity of the PTSS-10 instrument for PTSD may vary according to disease and other characteristics [31].

Recognition of the distinction between PTSD symptoms captured by the PTSS-10 and a PTSD diagnosis is vital, because this questionnaire does not give a DSM-IV diagnosis but only an indication of the level of PTSD symptomology. Clinically, a score on the PTSS-10 above the cutoff should prompt the attending physician to refer the patient to a psychologist to conduct a SCID [9].

Our results suggest that the (persisting) presence of traumatic memories is likely to be relevant to development of PTSD- related symptoms following a traumatic event, and not the ICU stay alone, because we observed a strong linear relationship between traumatic memories and PTSS-10 score. We assessed these traumatic memories (or adverse experiences) in accordance with patients' recollections. This may limit the conclusions one can make, because it is possible that perception of a traumatic experience may contribute to long-term PTSD symptomology, hence making a causal conclusion impossible.

Information concerning other unrelated traumatic experiences or life events that may have occurred after hospital admission was not collected. Therefore, the influence of superimposed trauma cannot be ruled out [6]. Also, because this was a retrospective study, it was also not possible to collect PTSD data on patients before their peritonitis. However, considering the acute nature of peritonitis, it would be difficult to collect such data even in a prospective trial. Given the impact of a severe life-threatening illness such as peritonitis, a relationship with the development of PTSD symptoms is plausible, but causality cannot be established when no information is available on other life events.

\section{Conclusion}

Nearly a quarter of patients receiving surgical treatment for secondary peritonitis developed PTSD symptoms. Considering the high long-term prevalence of PTSD, patients admitted to the ICU had a higher risk for PTSD symptoms but only after taking their higher age into account. Early detection of PTSD in peritonitis patients by questionnaires such as the PTSS-10 deserves attention.

\section{Key messages}

- In a cohort of 100 patients with secondary peritonitis, of whom 61 were admitted to the ICU and 39 were not (admitted to the surgical ward only), the overall prevalence of long-term PTSD symptomology using the PTSS-10 questionnaire was $24 \%$.

- In a univariate analysis we found no differences in PTSS-10 scores between ICU and non-ICU patients, but ICU stay was significantly associated with PTSD symptomology after adjusting for other factors related to PTSD, in particular age.

- There were no differences in the number of traumatic memories reported between ICU patients and patients managed on the surgical ward only, although we found a clear positive linear association between more traumatic memories and higher scores on the PTSS-10.

\section{Competing interests}

The authors declare that they have no competing interests. 


\section{Authors' contributions}

$\mathrm{MB}, \mathrm{DG}, \mathrm{MV}$ and $\mathrm{BL}$ designed the study and advised on surgical and ICU information; all information pertaining to surgical procedures and ICU stay for the final manuscript were considered by $\mathrm{MB}$ and $\mathrm{BL}$. $\mathrm{CM}, \mathrm{BL}$ and $\mathrm{CU}$ were responsible for the coordination of the study. CU and CM contacted patients, and collected and entered data. MS and CB advised for all quality of life and PTSD issues. KB, HR and MB analyzed data, and $\mathrm{KB}$ was responsible for the final manuscript. $\mathrm{KB}, \mathrm{CB}, \mathrm{HR}, \mathrm{MS}$ and $\mathrm{MB}$ interpreted and discussed all data. All authors read and approved the final manuscript.

\section{References}

1. Lamme B, Boermeester MA, Belt EJ, van Till JW, Gouma DJ, Obertop $\mathrm{H}$ : Mortality and morbidity of planned relaparotomy versus relaparotomy on demand for secondary peritonitis. $\mathrm{Br} J$ Surg 2004, 91:1046-1054.

2. Haraldsen $P$, Andersson R: Quality of life, morbidity, and mortality after surgical intensive care: a follow-up study of patients treated for abdominal sepsis in the surgical intensive care unit. Eur J Surg Supp/ 2003, 588:23-27.

3. Capuzzo M, Valpondi V, Cingolani E, Gianstefani G, De Luca S, Grassi L, Alvisi R: Post-traumatic stress disorder-related symptoms after intensive care. Minerva Anestesiol 2005, 71:167-179.

4. Cuthbertson $\mathrm{BH}$, Hull A, Strachan M, Scott J: Post-traumatic stress disorder after critical illness requiring general intensive care. Intensive Care Med 2004, 30:450-455.

5. Nickel M, Leiberich P, Nickel C, Tritt K, Mitterlehner F, Rother W, Loew T: The occurrence of posttraumatic stress disorder in patients following intensive care treatment: a cross-sectional study in a random sample. J Intensive Care Med 2004, 19:285-290.

6. Schelling G, Stoll C, Haller M, Briegel J, Manert W, Hummel T, Lenhart A, Heyduck M, Polasek J, Meier M, et al.: Health-related quality of life and posttraumatic stress disorder in survivors of the acute respiratory distress syndrome. Crit Care Med 1998, 26:651-659.

7. Schelling G, Richter M, Roozendaal B, Rothenhausler HB, Krauseneck T, Stoll C, Nollert G, Schmidt M, Kapfhammer HP: Exposure to high stress in the intensive care unit may have negative effects on health-related quality-of-life outcomes after cardiac surgery. Crit Care Med 2003, 31:1971-1980.

8. Scragg $\mathrm{P}$, Jones A, Fauvel N: Psychological problems following ICU treatment. Anaesthesia 2001, 56:9-14.

9. American Psychiatric Association: Diagnostic and Statistical Manual of Mental Disorders. Post-traumatic Stress Disorder Syndrome Washington DC: Harcourt Assessment BV; 1994.

10. Deja M, Denke C, Weber-Carstens S, Schroeder J, Pille CE, Hokema F, Falke KJ, Kaisers U: Social support during intensive care unit stay might reduce the risk for the development of posttraumatic stress disorder and consequently improve health related quality of life in survivors of acute respiratory distress syndrome. Crit Care 2006, 10:R147.

11. Kapfhammer HP, Rothenhausler HB, Krauseneck T, Stoll C, Schelling G: Posttraumatic stress disorder and health-related quality of life in long-term survivors of acute respiratory distress syndrome. Am J Psychiatry 2004, 161:45-52.

12. Schelling G, Stoll C, Kapfhammer HP, Rothenhausler HB, Krauseneck T, Durst K, Haller M, Briegel J: The effect of stress doses of hydrocortisone during septic shock on posttraumatic stress disorder and health-related quality of life in survivors. Crit Care Med 1999, 27:2678-2683.

13. Alonso J, Angermeyer MC, Bernert S, Bruffaerts R, Brugha TS, Bryson H, de Girolamo G, Graaf R, Demyttenaere K, Gasquet I, et al:: Disability and quality of life impact of mental disorders in Europe: results from the European Study of the Epidemiology of Mental Disorders (ESEMeD) project. Acta Psychiatr Scand Supp/ 2004, 420:38-46.

14. Andrews P, Azoulay E, Antonelli M, Brochard L, Brun-Buisson C, Dobb G, Fagon JY, Gerlach H, Groeneveld J, Mancebo J, et al.: Year in review in intensive care medicine, 2004. III. Outcome,
ICU organisation, scoring, quality of life, ethics, psychological problems and communication in the ICU, immunity and hemodynamics during sepsis, pediatric and neonatal critical care, experimental studies. Intensive Care Med 2005, 31:356-372.

15. Weisaeth L: The stressors and the post-traumatic stress syndrome after an industrial disaster. Acta Psychiatr Scand Suppl 1989, 355:25-37.

16. Weisaeth L: Torture of a Norwegian ship's crew. The torture, stress reactions and psychiatric after-effects. Acta Psychiatr Scand Supp/ 1989, 355:63-72.

17. Stoll C, Kapfhammer HP, Rothenhausler HB, Haller M, Briegel J, Schmidt M, Krauseneck T, Durst K, Schelling G: Sensitivity and specificity of a screening test to document traumatic experiences and to diagnose post-traumatic stress disorder in ARDS patients after intensive care treatment. Intensive Care Med 1999, 25:697-704.

18. Horowitz MJ, Wilner N, Kaltreider N, Alvarez W: Signs and symptoms of posttraumatic stress disorder. Arch Gen Psychiatry 1980, 37:85-92.

19. Stein MB, Walker JR, Hazen AL, Forde DR: Full and partial posttraumatic stress disorder: findings from a community survey. Am J Psychiatry 1997, 154:1114-1119.

20. Brown L, Cai TT, DasGupta A: Interval estimation for binomial proportion. Stat Sci 2001, 16:101-133.

21. Rattray JE, Johnston M, Wildsmith JA: Predictors of emotional outcomes of intensive care. Anaesthesia 2005, 60:1085-1092.

22. van der Ploeg E, Mooren TT, Kleber RJ, van der Velden PG, Brom $D$ : Construct validation of the Dutch version of the impact of event scale. Psychol Assess 2004, 16:16-26.

23. Schelling G, Kilger E, Roozendaal B, de Quervain DJ, Briegel J, Dagge A, Rothenhausler HB, Krauseneck T, Nollert G, Kapfhammer HP: Stress doses of hydrocortisone, traumatic memories, and symptoms of posttraumatic stress disorder in patients after cardiac surgery: a randomized study. Biol Psychiatry 2004, 55:627-633.

24. Breslau J, Kendler KS, Su M, Gaxiola-Aguilar S, Kessler RC: Lifetime risk and persistence of psychiatric disorders across ethnic groups in the United States. Psychol Med 2005, 35:317-327

25. Alonso J, Angermeyer MC, Bernert S, Bruffaerts R, Brugha TS, Bryson H, de Girolamo G, Graaf R, Demyttenaere K, Gasquet I, et al.: 12-Month comorbidity patterns and associated factors in Europe: results from the European Study of the Epidemiology of Mental Disorders (ESEMeD) project. Acta Psychiatr Scand Supp/ 2004, 420:28-37.

26. Alonso J, Angermeyer MC, Bernert S, Bruffaerts R, Brugha TS, Bryson H, de Girolamo G, Graaf R, Demyttenaere K, Gasquet I, et al.: Prevalence of mental disorders in Europe: results from the European Study of the Epidemiology of Mental Disorders (ESEMeD) project. Acta Psychiatr Scand Suppl 2004, 420:21-27.

27. Perkonigg A, Kessler RC, Storz S, Wittchen HU: Traumatic events and post-traumatic stress disorder in the community: prevalence, risk factors and comorbidity. Acta Psychiatr Scand 2000, 101:46-59.

28. Alonso J, Angermeyer MC, Bernert S, Bruffaerts R, Brugha TS, Bryson H, de Girolamo G, Graaf R, Demyttenaere K, Gasquet I, et al.: Use of mental health services in Europe: results from the European Study of the Epidemiology of Mental Disorders (ESEMeD) project. Acta Psychiatr Scand Suppl 2004 420:47-54.

29. Liberzon I, Abelson JL, Amdur RL, King AP, Cardneau JD, Henke $P$, Graham LM: Increased psychiatric morbidity after abdominal aortic surgery: risk factors for stress-related disorders. J Vasc Surg 2006, 43:929-934.

30. Stoll C, Haller M, Briegel J, Meier M, Manert W, Hummel T, Heyduck $M$, Lenhart A, Polasek J, Bullinger $M$, et al.: Health-related quality of life. Long-term survival in patients with ARDS following extracorporeal membrane oxygenation (ECMO) [in German]. Anaesthesist 1998, 47:24-29.

31. Whiting P, Rutjes AW, Reitsma JB, Glas AS, Bossuyt PM, Kleijnen $\mathrm{J}$ : Sources of variation and bias in studies of diagnostic accuracy: a systematic review. Ann Intern Med 2004, 140:189-202. 